\title{
DESENVOLVIMENTO DO ACERVO INFORMACIONAL DO IFBA NA ÓTICA DOS RESPONSÁVEIS PELAS BIBLIOTECAS
}

DEVELOPMENT OF THE INFORMATIONAL ACQUIS OF THE IFBA IN THE OPINION OF THE LIBRARIES RESPONSIBLE

${ }^{1}$ Bonifácio Chaves de Almeida

${ }^{2}$ Raymundo das Neves Machado

Instituto Federal de Educação, Ciência e Tecnologia da Bahia ${ }^{1}$

Universidade Federal da Bahia ${ }^{2}$

\section{Correspondência \\ Bonifácio Chaves de Almeida \\ Instituto Federal de Educação, Ciência e \\ Tecnologia da Bahia. \\ Salvador, BA. \\ E-mail: bonifaciochaves@yahoo.com.br}

Submetido em: 14/07/2018

Aceito em: 23/08/2018

Publicado em: 27/09/2018

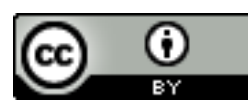

JITA: DD. Academic libraries / JA. Acquisitions 


\section{RESUMO}

Com o objetivo de investigar a percepção dos responsáveis pelas bibliotecas dos campi do Instituto Federal de Educação, Ciência e Tecnologia da Bahia (IFBA), no que tange aos procedimentos para a formação e desenvolvimento da coleção de material informacional da autarquia e a comparação dessa percepção com os preceitos da literatura da área, foi realizada uma pesquisa com a população de representantes das bibliotecas da instituição, metodologicamente caracterizada como exploratória no que tange aos objetivos, quantitativa no que se refere à abordagem do problema e de levantamento ou survey, quanto aos procedimentos. De início, conjecturou-se que, na visão dos representantes dessas bibliotecas, as bases teóricas acerca do tema eram empregadas com parcimônia e que não assentia a construção do acervo informacional colaborativo das unidades, apesar da estrutura multicampi do IFBA. Os resultados, alcançados a partir da análise de dados correlatos por meio da proposta de Macnaughton e do oscilador estocástico de Wilder Júnior, apontaram para algumas variáveis o emprego moderado, para outras o uso apresenta robusteza e em algumas variáveis a empregabilidade do ensinamento teórico-conceitual, quanto ao gerenciamento da coleção informacional, é frágil.

\section{PALAVRAS-CHAVE}

Bibliotecas - Desenvolvimento da coleção. Bibliotecas escolares. Bibliotecas universitárias.

\section{ABSTRACT}

In order to investigate the perception of those responsible for the libraries of the campuses of the Federal Institute of Education, Science and Technology of Bahia (IFBA) regarding the procedures for training and development of informational material's collection authority and the comparison between this perception and the precepts of it's field's literature, a survey of the population of representatives of libraries of the institution was carried out, methodologically characterized as exploratory in relation to the objectives, quantitative in relation to the problem approach. Initially, it is conjectured that, from the point of view of the representatives of these libraries, the theoretical basis of the topic was used sparingly and not agreed to the construction of collaborative informational collection of the units, despite the multicampi structure of IFBA. The results, obtained from the related data analysis through the proposed Macnaughton and Stochastic Oscillator of Wilder Jr., pointed to some moderate employment for some variables, a robust employment for others and, for the rest, the employability of the theoretical and conceptual teaching about the management of how the information collection is fragile.

\section{KEYWORDS}

Libraries - Development of collection. School libraries. University libraries. 


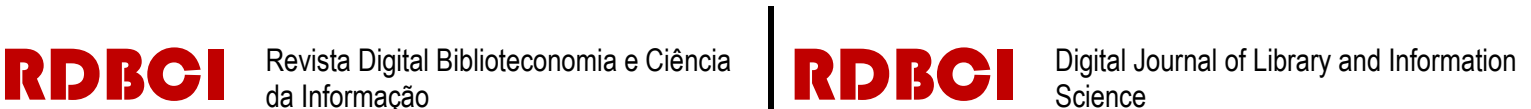

\section{INTRODUÇÃO}

A formação ou o desenvolvimento do acervo informacional é composto por um conjunto de ações empreendidas por um organismo informacional, no caso em pauta, bibliotecas de uma autarquia federal. Quanto aos aspectos funcionais das atividades o bibliotecário exerce um papel relevante no desenvolvimento das coleções, visto que conhece o meio ambiente no qual a biblioteca está inserida e, principalmenmte, tem condições de identificar as múltiplas necessidades informacionais de sua comunidade de usuários.

Vergueiro (2010) entende que a decisão de incorporar um item informacional à coleção transfigura no poder dado ao bibliotecário de interferir nas relações sociais dos indivíduos e nos desenlaces do seu trabalho e, por conseguinte, nas benesses que poderão advir para toda a humanidade. Destaca, ainda, que a decisão de seleção de determinado item informacional poderá, em muitos casos, não possuir o mesmo vigor se tomada em momento inoportuno.

Andrade e Vergueiro (1996), confirmando a importância de se estudar os processos de aquisição, percebem ser, a partir da aquisição, que as bibliotecas iniciam sua trajetória no labor da garantia da custódia, do acesso e da disponibilidade do conhecimento humano registrado, sem desprezar a decisão do profissional em escolher um determinado item em detrimento a outro, com vista à gama de material produzido, o objetivo institucional e a disponibilidade orçamentária.

A quantidade vertiginosa de produção informacional, também, mostra-se como comprovante para se debruçar acerca do assunto. Afinal, é indubitável a incapacidade organizacional de custódia de todo o conhecimento humano, aliada à insuficiência de recursos econômicos para sua aquisição.

Esta pesquisa procurou investigar a percepção dos responsáveis pelas bibliotecas dos campi do Instituto Federal de Educação, Ciência e Tecnologia da Bahia (Ifba) no que tange aos procedimentos para formação e desenvolvimento da coleção de material informacional da autarquia e a comparação dessa percepção com os preceitos da literatura da área. Essa escolha, em detrimento ao conjunto de todos os seus profissionais, é justificada pela sua posição estratégica e decisória na seção, influenciando a determinação do encerramento do ato administrativo, independente de participação dos outros componentes da equipe.

Do ponto de vista prático, espera-se que a instituição estudada se beneficie com as reflexões proporcionadas pelo trabalho, no que concerne a repensar suas rotinas administrativas, visando a cooperação entre as suas diversas bibliotecas, compartilhamento dos recursos informacionais, financeiros e de investimentos na sua infraestrutura de bibliotecas. Os

\begin{tabular}{l|l|l|l|l|l|}
\hline (c) RDBCl: Rev. Digit. Bibliotecon. Cienc. Inf. & Campinas, SP & v.17 & $1-21$ & e019001 & 2019 \\
\hline
\end{tabular}




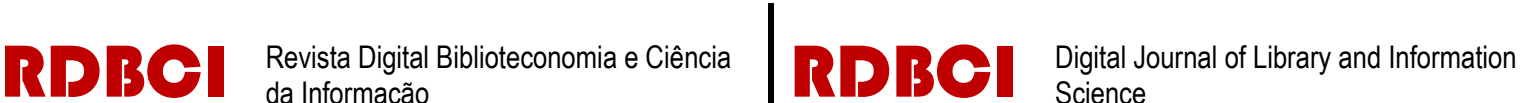

ajuizamentos poderão, ainda, trilhar o subsídio a instituições que possuam estruturas de bibliotecas semelhantes à da organização pesquisada ou que iniciarão o processo de formação e desenvolvimento de suas coleções de materiais informacionais.

Poderá, também, contribuir para o desenvolvimento de projetos de formação da Política de Desenvolvimento de Coleções (PDC) da instituição e na política de capacitação e qualificação dos seus servidores, com o objetivo de sanar possíveis ausências na formação de seus profissionais, reverberando na qualidade dos serviços ofertados à comunidade pelas bibliotecas. Ainda, poderá, igualmente, servir como referência em futuros trabalhos no campo da formação e desenvolvimento de coleções do acervo das bibliotecas.

Este artigo, além desta seção introdutória, está organizado em mais quatro partes. A segunda inicia o referencial teórico, apresenta brevemente as características das bibliotecas existentes no Ifba e cuida dos conceitos canônicos acerca da formação e do desenvolvimento das coleções de materiais informacionais. A terceira seção traz o arcabouço metodológico da pesquisa, apresenta os atributos metodológicos do estudo; seu instrumento de investigação, incluindo informações e técnicas estatísticas utilizadas na análise e interpretação dos dados. A descrição e análise dos dados são expostas na quarta seção. Na quinta seção, são apresentadas as considerações finais e conclusões da pesquisa, suas limitações e sugestões para pesquisas vindouras. Por fim, a lista de referências dos itens citados.

\section{GERENCIAMENTO DE COLEÇÃO: DA COGNIÇÃ̃ À BUROCRACIA}

A visão de bibliotecas, arquivos e centros de documentação evolue com o crescimento social, deixando de ser agentes de custódia da informação para se comportarem como facilitadores e mediadores da informação, desejosos por apresentar resposta às necessidades dos seus usuários (RIBEIRO, 2010).

Para Vergueiro (1993) o desenvolvimento da coleção, antes da explosão bibliográfica, não possuía uma técnica sistemática, a exemplo do que acontecia com a catalogação. Seguia a lei da formação livre (laissez-faire) impulsionada pela gana de aquisição descontrolada, produzindo uma quantidade de material de informação redundante, sem um estudo pormenorizado do que se deveria adquirir e do usuário a quem se destinaria a informação.

A explosão da editoração e disseminação informacional foi um dos fatores, talvez o principal, que levou os profissionais da informação a repensar suas técnicas e métodos de aquisição, formação e desenvolvimento de coleções, incorporada à escassez de pessoal, infraestrutura e recursos financeiros. Burke (2002) se alia ao pensamento de que a imprensa 


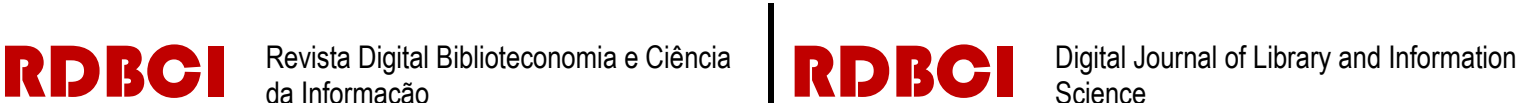

revolucionou o aparelhamento da biblioteca e a profissão de bibliotecário; sua organização de trabalho, cooperação, de caráter antes generalista agora especializado e, por conseguinte, promoveu a mudança do paradigma dos serviços de informação ofertados pelas bibliotecas, antes de custódia, presentemente, pós-custodial, no qual o usuário passa a ser o centro das atenções. Já Weitzel (2012), afirma que o excesso de publicações repercutiu no formar e desenvolver das coleções das bibliotecas, agora mais difícil, carecendo do discernimento de qual obra era merecedora de ser agregada à coleção, contrariando a visão pretérita à propulsão editorial, na qual, dada a escassez, satisfazia-se em localizar títulos publicados e acumulá-los.

Não obstante, está presente, em todos os tipos de bibliotecas, a filosofia do desenvolvimento de coleção é diferente para cada proposição, tendo em vista as características intrínsecas às funções que essas bibliotecas se dispõem a desempenhar.

O percurso histórico do Ifba, assim como aconteceu em outras autarquias de ensino técnico federal, harmonizou a oferta diversificada de cursos e de modalidades de ensino, refletindo nas estruturas administrativas da organização, em especial na função de suas bibliotecas. Alinhado com os objetivos da instituição pesquisada, suas bibliotecas possuem essencialmente a tipologia amalgamada de biblioteca escolar e de biblioteca universitária, coexistindo em uma única edificação.

A exemplo dos dois tipos de bibliotecas alvo nesse estudo, a escolar e a universitária, destaca-se que na primeira o processo de desenvolvimento da coleção estará alinhado com o currículo escolar, com o objetivo de apoio às atividades didáticas e o desbastamento da coleção acontecerá em sincronia com a alteração do programa escolar. $\mathrm{Na}$ segunda, a biblioteca universitária, deve atender à tríade de pesquisa, ensino e extensão, carecendo de uma gama de material mais volumoso, tendo em vista a necessidade heterogênea das pesquisas e os pontos fortes do assunto no seu desenvolvimento.

De acordo com Evans (1995), a consecução do desenvolvimento da coleção é feita a partir das atividades de estudo de comunidade, políticas de seleção, seleção, aquisição, desbastamento e avaliação, todas suportadas pelas atuações do profissional bibliotecário, subsidiadas pela comunidade receptora dos serviços da biblioteca com exceção do processo de aquisição. A caracterização do processo feita pelo autor, em círculo, pressupõe que todas as atividades operam em pé de igualdade e em processo ininterrupto.

O estudo de comunidade deve ser suportado por informações capazes de identificar o gosto e as precisões da comunidade e, dessa forma, eleger as primazias de incorporação ao seu acervo. Como base nessas informações, produtos e serviços informacionais são eladorados visando a comunidade de usuários. O referido estudo é uma premissa de total relevância para o corpo técnico encarregado de formar e desenvolver as coleções, bem como é importante o

\begin{tabular}{c|c|c|c|c|c}
\hline (c) RDBCl: Rev. Digit. Bibliotecon. Cienc. Inf. & Campinas, SP & v.17 & $1-21$ & e019001 & 2019 \\
\hline
\end{tabular}




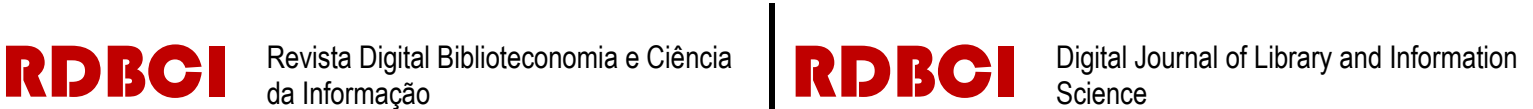

seu constante monitoramento, identificando, também, o comportamento de informação e comunicação e os potenciais dos usuários dessas observações quando analisadas devera subsidiar a tomada de descisão no precesso seletivo dos entes que irão compor o acervo.

A PDC é o documento formalizado institucionalmente para o desenvolvimento de coleções, devendo conter os procedimentos para cada ação que compõem a formação e o desenvolvimento de coleções bem os responsaveis pela excusão das mesmas. Kennedy (2006) concebe esse documento "como declarações escritas das políticas destinadas a gerenciar as atividades de uma biblioteca em relação à sua coleção". Para Lorenzen (2009) a política visa o planelametno do acervo informacional de uma biblioteca visto que garante a consistência das atividades. Hoffmann e Wood (2005) sinalizam a relevância da política como instrumento de comunicação da biblioteca com sua comundiade.

A seleção de materiais informacionais deve estar pautada na objetividade que a escolha ou rechaço do item acarretará ao acervo de uma biblioteca, com foco na comunidade a ser servida, desprovida dos modismos propalados pelas inovações tecnológicas ou aquisição sem critérios suportadas pela disponibilidade orçamentária. Não obstante, o objetivismo norteador do processo é indubitável à existência do subjetivismo ou discricionariedade do bibliotecário ou comissão de seleção projetada pela impossibilidade de aquisição de todo o material produzido pela humanidade, limitado, parcialmente, pelos critérios de seleção previamente definidos.

Estabel e Moro (2014) apontam a exigência de imparcialidade no processo de seleção do material informacional, observada a valoração que o item trará ao acervo, com vistas aos objetivos da biblioteca, sua necessidade e valor agregado em comparação com o acervo existente. Os autores (2014) pontuam, ainda, a importância do olhar quantitativo e qualitativo do acervo informacional e que a seleção não se realiza em um momento estanque, faz-se presente em outros fazeres dos servidores da biblioteca. Vergueiro (2010) aponta a objetividade, a qualidade e a necessidade como regras a serem seguidas na seleção. A PDC é o documento institucional que regulamenta todas as etapas de gerenciamento do acervo informacional no qual deve apontar a política de seleção.

Considerando as exigências impostas pela Diretoria de Avaliação da Educação Superior (Daes), vinculada ao Instituto Nacional de Estudos e Pesquisas Educacionais Anísio Teixeira (Inep), nas quais a valoração da coleção informacional se baseia no quantitativo das publicações sugeridas nas ementas básicas e complementares dos componentes curriculares quando na avaliação in loco dos cursos (DAES, 2015), é atrativo a formação de uma equipe multiprofissional para realização da tarefa, presidida pelo bibliotecário, incluindo representantes docentes, dada a impossibilidade de participação de todo o corpo docente, e no momento da reformulação dos currículos e suas ementas a equipe de seleção e o bibliotecário

\begin{tabular}{l|l|l|l|l|l}
\hline (c) RDBCl: Rev. Digit. Bibliotecon. Cienc. Inf. & Campinas, SP & v.17 & $1-21$ & e019001 & 2019 \\
\hline
\end{tabular}




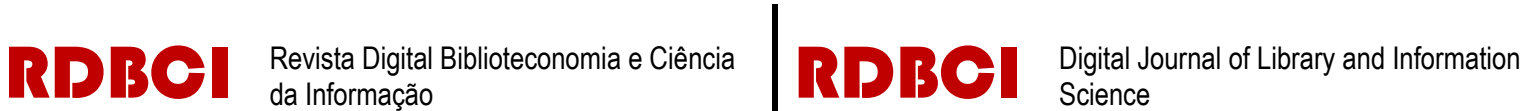

de seleção participem dessa construção, com a intenção de adjetivar a coleção qualitativamente e quantitativamente, inibindo a indicação de itens que guardem similaridade com outros que a unidade já possua e que atenda a demanda do componente curricular. A importância da atuação do bibliotecário no processo de seleção de um componente informacional é defendida por Vergueiro (2010) em função de seu conhecimento das potencialidades e fraquezas do acervo da unidade e dos usuários a quem atende e suas necessidades e, mesmo que a decisão final não seja a ele contemplada, sua participação será exercida.

Por sua vez, o processo de aquisição é o artifício inicial para que o acervo e, consequentemente, uma biblioteca se transforme de uma idealização para a concretude. Nas palavras de Andrade e Vergueiro (1996, p. 6) é a segurança "que o planejamento nas fases anteriores do desenvolvimento de coleções, principalmente as fases de elaboração da política e a atividade de seleção, propriamente dita, seja colocado em prática."

Diferenciando das demais etapas que compoem o ciclo do gerenciamento da coleção, a aquisição é composta por ações administrativas que se distanciam da intervenção direta da comunidade. Apesar dessa particularidade de distanciamento da intervenção da comunidade e do usuário, não implica que a aquisição se comporte isolada das demais etapas do processo de gerenciamento do acervo ou que a ação seja meramente burocrática. Merecem relevo as ações de planejamento, elaboração, execução e avaliação orçamentária. Andrade e Vergueiro (1996) advogam que em muitas ocasiões é árdua a tarefa de distinguir as atividades de seleção das ações de aquisição e, nesse prisma, recomendam a proximidade ambiental as divisões administrativas dos dois eventos, justificada pela celeridade no processo decisório da seleção à aquisição. Na impossibilidade dessa circunvizinhança no organograma institucional, há de se garantir que a proximidade esteja presente no processo de comunicação, merecendo atenção o registro formal dos procedimentos de aquisição de material informacional.

Avaliar a coleção e repensar o propósito, os objetivos e missão da biblioteca, é primordial para averiguar se a unidade informacional permanece imperiosa ao desígnio de servir à comunidade a quem se propôs a atender e, particularmente, ao seu usuário. Nessa ótica, o acervo é o foco da avaliação por configurar uma das principais origens e manutenção do intercâmbio biblioteca versus comunidade/usuário; missão/objetivo da biblioteca versus interesses e demandas da comunidade/usuário, assim como contribui para a disseminação informacional e subsidia o planejamento e coerência das etapas de seleção, aquisição e desbastamento da PDC. Apesar da atenção voltada ao acervo, todos os serviços da biblioteca fazem jus ao processo avaliativo (FIGUEIREDO, 1979b, 1998).

No que concerne ao gerenciamento de um acervo informacional, o desbastamento se caracteriza por uma ação regulatória da coleção, com vistas aos interesses da unidade, baseada em sua missão e seus objetivos, preocupada com o atendimento à demanda da comunidade $\mathrm{e}$ do usuário. $\mathrm{O}$ conhecimento do bibliotecário quanto à instituição mantenedora, a biblioteca e a

\begin{tabular}{l|l|l|l|l|l}
\hline (c) RDBCl: Rev. Digit. Bibliotecon. Cienc. Inf. & Campinas, SP & v.17 & $1-21$ & e019001 & 2019 \\
\hline
\end{tabular}


comunidade de usuários, efetivos ou potenciais, são primordiais para o gerenciamento da coleção de maneira holística, agregado, também, a sua formação, conhecimento, habilidade e prática de pesquisa.

\section{ESTRUTURA METODOLÓGICA}

Desde a sua fundação em 1909 por meio do Decreto $n^{\circ}$ 7.566/1909 e inagurado em 1910 sob a denominação de Escola de Aprendizes Artífices da Bahia, popularmente conhecida pelo nome de "Escola do Mingau" em função de seu caráter assistencialista, estampado no documento legal de sua criação e em virtude da alimentação por ela servida aos seus alunos, a história do Ifba é conexa à evolução do ensino profissional brasileiro. Teve sua nomenclatura alterada ao longo dos anos: Escola de Aprendizes Artífices da Bahia (1909), Liceu Industrial de Salvador (1937), Escola Técnica de Salvador (1942), Escola Técnica Federal da Bahia (1965), Centro Federal de Educação Tecnológica da Bahia (1993), Instiuto Federal de Educação, Ciência e Tecnologia da Bahia (2008). Além da alteração na razão social as modificações refletiam na oferta de cursos pela instituição e, por conseguinte, em suas bibliotecas.

Com status equiparado à universidade, o Ifba, à época do estudo (2016), se fazia presente nas cidades de Barreiras, Brumado, Camaçari, Euclides da Cunha, Eunápolis, Feira de Santana, Irecê, Ilhéus, Jacobina, Jequié, Juazeiro, Lauro de Freitas, Paulo Afonso, Porto Seguro, Salinas da Margarida, Salvador, Santo Amaro, Santo Antônio de Jesus, Seabra, Simões Filho, Ubaitaba, Valença e Vitória da Conquista.

Considerando as localizações geográficas dos campi do Ifba, optou-se pela observação indireta de coleta de dados por meio da aplicação de um questionário. Respaldado no referencial teórico, conceituação abstrata a fim de explicar a realidade, foram escolhidos os indicadores, atributos ou características que em comunhão com os objetivos da pesquisa orientaram a construção do questionário. Os indicadores ou componentes conceituais mensuráveis podem ser variáveis definidas - relacionadas diretamente com as hipóteses, e variáveis de controle - possuidores de interação com outras variáveis (QUIVY; CAMPENHOUDT, 1998).

O questionário é composto por três seções. Na seção introdutória é realizado um panorama da pesquisa, sua finalidade e os responsáveis pelo estudo, seguido do Termo de Consentimento Livre e Esclarecido no qual o questionado formaliza sua ciência acerca dos procedimentos de pesquisa e sua concordância voluntária ou desacordo com a participação. $\mathrm{Na}$ primeira parte das proposições é feita uma investigação acerca do perfil do respondente para

\begin{tabular}{c|c|c|c|c|c}
\hline C RDBCl: Rev. Digit. Bibliotecon. Cienc. Inf. & Campinas, SP & v.17 & $1-21$ & e019001 & 2019 \\
\hline
\end{tabular}




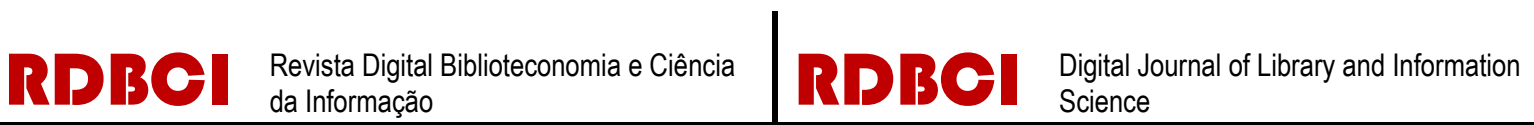

em seguida, na segunda parte das proposições, serem inquiridos sobre a problemática de pesquisa.

Com a finalidade de minimizar as possíveis inadequações, ambiguidades, omissões e carência de objetividade, precedente à sua aplicação, o instrumento de observação foi submetido à avaliação de um estudioso da área de Desenvolvimento de Coleções. Suas contribuições foram incorporadas ao questionário, a versão definitiva foi mais uma vez submetida ao apreço do parecerista e após sua aquiescência, submetida à população de questionados.

Todas as opiniões dos respondentes da segunda parte do questionário são aferidas por meio de escala tipo Likert composta da escala diferencial na qual a significação numeral é 1 Discordo Totalmente (DT), 2 - Discordo (D), 3 - Indiferente (I), 4 - Concordo (C) e 5 Concordo Totalmente (CT). Nas palavras de Sanches, Meireles e De Sordi (2011), uma escala do tipo Likert não possui 'questões' e sim assertivas nas quais o respondente indica seu grau de concordância. Para Likert (1976 apud SANCHES; MEIRELES; DE SORDI, 2011, p. 2), sua escala objetiva 'verificar o nível de concordância do sujeito com uma série de afirmações que expressem algo favorável ou desfavorável em relação a um objeto psicológico.' Essa descrição da finalidade da escala de medição abraça o propósito desta pesquisa, visto que sua análise é construída baseada nas perspectivas, opiniões dos respondentes, sem intervenção do pesquisador.

Considerando o quantitativo das bibliotecas de investigação, a pesquisa foi realizada com a todos os campi formadores do Ifba, a população, em detrimento à escolha de uma amostra representativa (QUIVY; CAMPENHOUDT, 1998). Dessa feita, foi solicitado à Gerência de Desenvolvimento de Bibliotecas (GDBIB) do Ifba o rol de campi da autarquia com bibliotecas em funcionamento, seus representantes e dados de contato. De acordo com o documento a Reitoria, o Núcleo Avançado Salinas das Margaridas, o Campus Avançado de Ubaitaba e os campi Polo de Inovação e Lauro de Freitas não possuem biblioteca ativa, logo, não circunscrevem a população alvo de pesquisa.

Perante a dispersão geográfica das bibliotecas que a princípio poderia se configurar como um entrave na condução da observação, e em harmonia com o atributo quantitativo da pesquisa se optou pela metodologia procedimental do levantamento ou survey. O questionário foi moldado no software SurveyMonkey ${ }^{\circledR}$ e remetido aos endereços eletrônicos. Constatou-se que uma biblioteca, contrariando a informação fornecida anteriormente, possuía a responsabilidade subdividida em duas, com foco no suporte informacional, e alinhado ao intuito da pesquisa em levantar a opinião dos responsáveis pelas bibliotecas dos campi do Ifba no que tange aos procedimentos para formação ou desenvolvimento da coleção de material informacional, o questionário foi encaminhado para os dois representantes.

\begin{tabular}{l|l|l|l|l|l}
\hline (c) RDBCl: Rev. Digit. Bibliotecon. Cienc. Inf. & Campinas, SP & v.17 & $1-21$ & e019001 & 2019 \\
\hline
\end{tabular}


A análise dos dados foi realizada a partir da proposta metodologica adotada por Sanches, Meirele e De Sordi (2011), tendo como referência o grau diferencial semântico empregado para ilustrar a opinião do questionado, e descreve número de discordantes e concordantes de cada proposição. A primeira etapa para o cálculo de Discordantes da proposição $\left(\mathrm{D}_{\mathrm{p}}\right)$ por meio da proposta de Macnaughton é somar os quantitativos das respostas DT e D e da metade dos valores I. O cálculo dos Concordantes da proposição $\left(\mathrm{C}_{\mathrm{p}}\right)$ é obtido de forma similar, ou seja, soma-se os valores de CT e C da metade dos valores de I. Já o 'sentido geral' das respostas é alcançado a partir da opinião do respondente equivalente ao valor total de respondentes dividido por 2 , no sentido da esquerda para a direita.

Por sua vez, oscilador estocástico ou indicador de força relativa sinaliza o Grau de Concordância da proposição $\left(\mathrm{GC}_{\mathrm{p}}\right)$ é obtido, adicionado 0,000001 aos valores de $\mathrm{C}_{\mathrm{p}}$ e $\mathrm{D}_{\mathrm{p}}$, com a finalidade de evitar erros de divisão (SANCHES; MEIRELES; DE SORDI, 2011).

A explicação do $\mathrm{GC}_{\mathrm{p}}$ é realizada a partir da convenção exposta no quadro 1 (SANCHES; MEIRELES; DE SORDI, 2011).

Quadro 1. Interpretação de valores do $\mathrm{GC}_{\mathrm{p}}$

\begin{tabular}{|c|l|}
\hline Valor de GC & \multicolumn{1}{c|}{ Frase Adequada } \\
\hline 90 ou mais & Uma concordância muito forte \\
\hline $80 \mathrm{a}+89,99$ & Uma concordância substancial \\
\hline $70 \mathrm{a}+79,99$ & Uma concordância moderada \\
\hline $60 \mathrm{a}+69,99$ & Uma concordância baixa \\
\hline $50 \mathrm{a}+59,99$ & Uma concordância desprezível \\
\hline $40 \mathrm{a}+49,99$ & Uma discordância desprezível \\
\hline $30 \mathrm{a}+39,99$ & Uma discordância baixa \\
\hline $20 \mathrm{a}+29,99$ & Uma discordância moderada \\
\hline $10 \mathrm{a}+19,99$ & Uma discordância substancial \\
\hline 9,99 ou menos & Uma discordância muito forte \\
\hline
\end{tabular}

Fonte: Sanches, Meireles e De Sordi (2011)

Sanches, Meireles e De Sordi (2011) afiançam a possibilidade de análise por meio da proposta de Macnaughton e do oscilador estocástico de Wilder Júnior para uma proposição ou para um fator. Denomina-se fator o conjunto de proposições acerca de um tópico. O cálculo dos discordantes do fator $\left(\mathrm{D}_{\mathrm{f}}\right)$, concordantes do fator $\left(\mathrm{C}_{\mathrm{f}}\right)$ e o Grau de Concordância do fator $\left(\mathrm{GC}_{\mathrm{f}}\right)$, adicionado 0,000001 aos valores de $\mathrm{C}_{\mathrm{f}}$ e $\mathrm{D}_{\mathrm{f}}$, com a finalidade de evitar erros de divisão. A mesma convenção do quadro 1 é empregada para a explicação do GC $_{f}$ (SANCHES; MEIRELES; DE SORDI, 2011). 


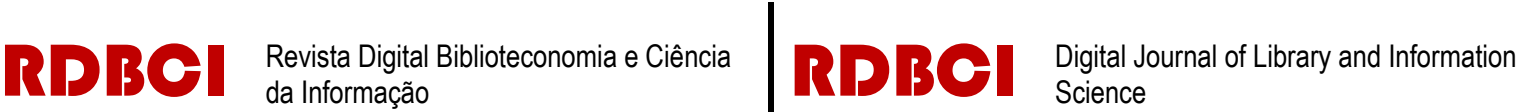

\section{ANÁLISES DOS DADOS}

Da população de 21 responsáveis por bibliotecas do Ifba, tendo em vista que uma biblioteca declarou responsabilidade compartilhada, responderam ao questionário 20 compartes e todos os partícipes declararam estarem de acordo em responder o questionário espontaneamente, ou seja, mais de $95 \%$ dos questionários enviados foram correspondidos. Desse número, 85\% dos responsáveis declararam ocuparem cargo de BibliotecárioDocumentalista.

De acordo com a alínea c do artigo $6^{\circ}$ da Lei no 4.084/1962, a direção e a administração de bibliotecas é competência do bacharel em Biblioteconomia (BRASIL, 1962). Frise-se que o dispositivo legal não prevê que a direção e a administração das bibliotecas sejam titulares de cargos de Bibliotecário-Documentalista, prevê, apenas, que estes sejam bacharéis em Biblioteconomia devidamente registrados no conselho de classe. Por sua vez, a Secretaria de Gestão Pública do Ministério do Planejamento, Orçamento e Gestão reforçou este entendimento ao orientar aos órgãos vinculados ao Sistema de Pessoal Civil da Administração Federal que a administração e direção das bibliotecas sejam ocupadas por bibliotecários com registro no Conselho Regional de Biblioteconomia da jurisdição (BRASIL, 2012), permanecendo silente quanto à exigência dessa função ser titular do cargo de BibliotecárioDocumentalista.

Quando questionados acerca da existência específica de disciplina voltada à Formação e Desenvolvimento de Coleções nos currículos dos cursos de Biblioteconomia, apenas um respondente que declarou ocupar o cargo de Bibliotecário-Documentalista ignorou essa informação. Logo, dos 17 ocupantes titulares deste cargo, 94,1\% afirmaram terem cursado disciplinas voltadas ao tema em análise durante a sua graduação. Esse resultado de valoração curricular no que tange à formação e desenvolvimento de coleções, incluindo atividades acessórias ao processo como a bibliometria, a preservação e conservação, comunga com as opiniões de Evans (1995), Vergueiro (2010) e Machado e Santos (2002) ao assinalarem o bibliotecário como ator principal para a realização dessas ações.

Do total de respondentes, 50\% afirmaram possuír título de especialista, ao passo que $15 \%$ declaram ser detentores do título de mestre. Portanto $65 \%$ dos questionados, coerentemente com a importância à formação inicial, preocupam-se em se manter atualizados no que tange à sua qualificação profissional. Essa atitude dos respondentes é esposada por Figueiredo (1979a; 1998) ao defender que para o gerenciamento da coleção, além das necessidades legais que carecem atenção ao tratamento do acervo informacional dessas bibliotecas, considerando seu mantenedor ser órgão da administração pública, requer do 
profissional da informação o desenvolvimento de habilidades e competências, incluindo no que tange às técnicas e métodos de pesquisa e estatística.

De acordo os respondentes, o sentimento predominante é de concordância (C) com relação ao conhecimento acerca das questões relacionadas com a formação $\mathrm{e} o$ desenvolvimento de coleções de bibliotecas. Esse sentimento é corroborado pelo valor de $\mathrm{C}_{\mathrm{p}}$, já que 18 dos 20 questionados responderam concordantemente e o valor do $\mathrm{GC}_{\mathrm{p}}(90)$ indica a existência de uma concordância muito forte para a proposição em tela.

Baseado na análise dos dados por meio da proposta de Macnaughton e do oscilador estocástico de Wilder Júnior da proposição acerca a necessidade do estudo de comunidade da biblioteca (Tabela 1), as respostas dos questionados se dirigem ao preceito apontado pela literatura uma vez que $100 \%$ dos questionados discordam da desnecessidade de promoção do estudo da comunidade, apesar das bibliotecas do Ifba se enquadrarem como universitárias e escolares, tipologias que ensejam uma facilidade no reconhecimento quanto a comunidade a ser atendida, caracterizando um sentimento geral de discordância total (DT) quanto à assertiva e uma discordância muito forte, conforme $\mathrm{GC}_{\mathrm{p}}$.

Tabela 1. Análise acerca da necessidade de realização do estudo da comunidade

\begin{tabular}{|c|c|c|c|c|c|c|c|c|c|c|}
\hline \multirow{2}{*}{$\begin{array}{c}\text { Considerando o ambiente } \\
\text { organizacional, } \\
\text { estrutura multicampi do Ifba e por } \\
\text { se tratar de uma biblioteca que } \\
\text { serve a uma instituição de ensino } \\
\text { não há necessidade para realização } \\
\text { do estudo da comunidade }\end{array}$} & \multicolumn{5}{|c|}{ Diferencial Semântico } & \multirow[b]{2}{*}{ 隐 } & \multirow{2}{*}{ 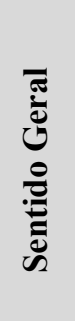 } & \multirow{2}{*}{ 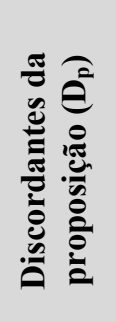 } & \multirow{2}{*}{ 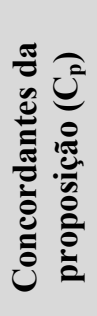 } & \multirow{2}{*}{ 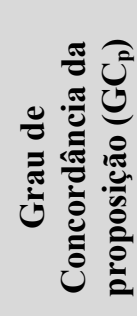 } \\
\hline & $\begin{array}{l}5 \\
1 \\
-1\end{array}$ & $\begin{array}{l}0 \\
1 \\
\sim\end{array}$ & $\begin{array}{c}T \\
\text { n }\end{array}$ & $\begin{array}{l}u \\
1 \\
+\end{array}$ & $\begin{array}{c}E \\
1 \\
1 \\
n\end{array}$ & & & & & \\
\hline Freq & 15 & & & 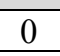 & & & \multirow{2}{*}{ DT } & \multirow{2}{*}{20} & & \multirow{2}{*}{0,0} \\
\hline Percentual & 75 & & 0 & 0 & 0 & 10 & & & & \\
\hline
\end{tabular}

Fonte: Os autores, pesquisa de campo.

Quando questionado acerca da existência da PDC formalizada, o sentimento prioritário dos respondentes foi de indiferença. $\mathrm{O} \mathrm{GC}_{\mathrm{p}}(47,5)$ apontou uma discordância desprezível, corroborado pelo $\mathrm{D}_{\mathrm{p}}(10,5)$ que indicou que 10,5 dos 20 partícipes da pesquisa discordaram da existência formal do dispositivo, como ilustra a tabela 2. 
Tabela 2. Análise acerca da formalização da PDC

\begin{tabular}{|c|c|c|c|c|c|c|c|c|c|c|}
\hline \multirow[b]{2}{*}{$\begin{array}{c}\text { A biblioteca possui uma política de } \\
\text { desenvolvimento de coleções (PDC) } \\
\text { formalizada }\end{array}$} & \multicolumn{5}{|c|}{ Diferencial Semântico } & \multirow[b]{2}{*}{ 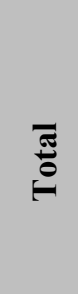 } & \multirow{2}{*}{ 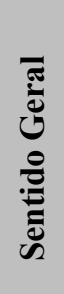 } & \multirow{2}{*}{ 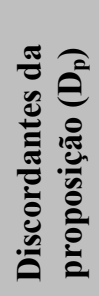 } & \multirow{2}{*}{ 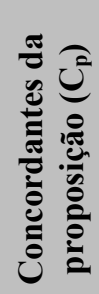 } & \multirow{2}{*}{ 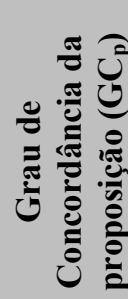 } \\
\hline & 占 & $\stackrel{0}{1}$ & $\vec{r}$ & $\begin{array}{l}0 \\
1 \\
+\end{array}$ & $\begin{array}{c}0 \\
\text { U } \\
1 \\
\text { n }\end{array}$ & & & & & \\
\hline Frequência & 2 & 6 & 5 & 3 & 4 & 20 & \multirow{2}{*}{ I } & \multirow{2}{*}{10,5} & \multirow{2}{*}{9,5} & \multirow{2}{*}{47,5} \\
\hline Percentual & 10 & 30 & 25 & 15 & 20 & 100 & & & & \\
\hline
\end{tabular}

Fonte: Os autores, pesquisa de campo.

A PDC é o instrumento formal que coordena o desenvolvimento da coleção em sintonia com os objetivos da biblioteca e efetividade na utilização dos recursos disponíveis, frente à impossibilidade de aquisição de toda produção informacional (WEITZEL, 2002, 2012). Assim, na percepção dos respondentes, as bibliotecas do Ifba a recomendação dos estudiosos do tema não se reflete na prática.

A tabela 3 compila os dados das proposições relacionadas ao fator seleção de materiais informacionais. Vergueiro (2010) defende a representação do bibliotecário no processo de seleção para a biblioteca por considerar a capacidade do profissional quanto ao conhecimento do acervo e do perfil da comunidade/usuário.

Considerando os dados apresentados na tabela 3, do total de 100 respostas que compõem o fator $\mathrm{C}_{\mathrm{f}}=64,5$ dessas respostas, de meneira geral, concordam com o fator, ao passo que $\mathrm{D}_{\mathrm{f}}$ $=35,5$ das respostas discordam com o fator. Pode-se, ainda, afirmar que existe uma concordância baixa dos respondentes com relação a todas as proposições desse fator.

Tabela 3. Análise do fator Seleção de materiais informacionais

\begin{tabular}{|c|c|c|c|c|c|c|c|c|c|}
\hline \multirow[b]{2}{*}{ Proposição } & \multicolumn{5}{|c|}{ Diferencial Semântico } & \multirow[b]{2}{*}{ } & \multirow{2}{*}{ 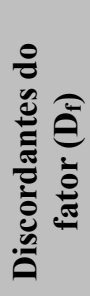 } & \multirow{2}{*}{ 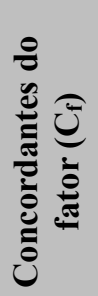 } & \multirow{2}{*}{ 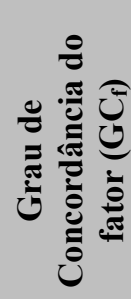 } \\
\hline & $\stackrel{5}{1}$ & $\underset{1}{1}$ & r & $\begin{array}{l}u \\
1 \\
+\end{array}$ & $\begin{array}{c}0 \\
1 \\
n\end{array}$ & & & & \\
\hline $\begin{array}{l}\text { A biblioteca é representada durante o processo } \\
\text { de seleção do material informacional que será } \\
\text { agregado ao acervo informacional }\end{array}$ & 1 & 3 & 2 & 6 & 8 & 20 & \multirow{2}{*}{35,5} & \multirow{2}{*}{64,5} & \multirow{2}{*}{64,5} \\
\hline $\begin{array}{l}\text { A seleção do material informacional procura } \\
\text { atender exclusivamente às ementas dos } \\
\text { componentes curriculares dos cursos }\end{array}$ & 4 & 4 & 2 & 7 & 3 & 20 & & & \\
\hline
\end{tabular}




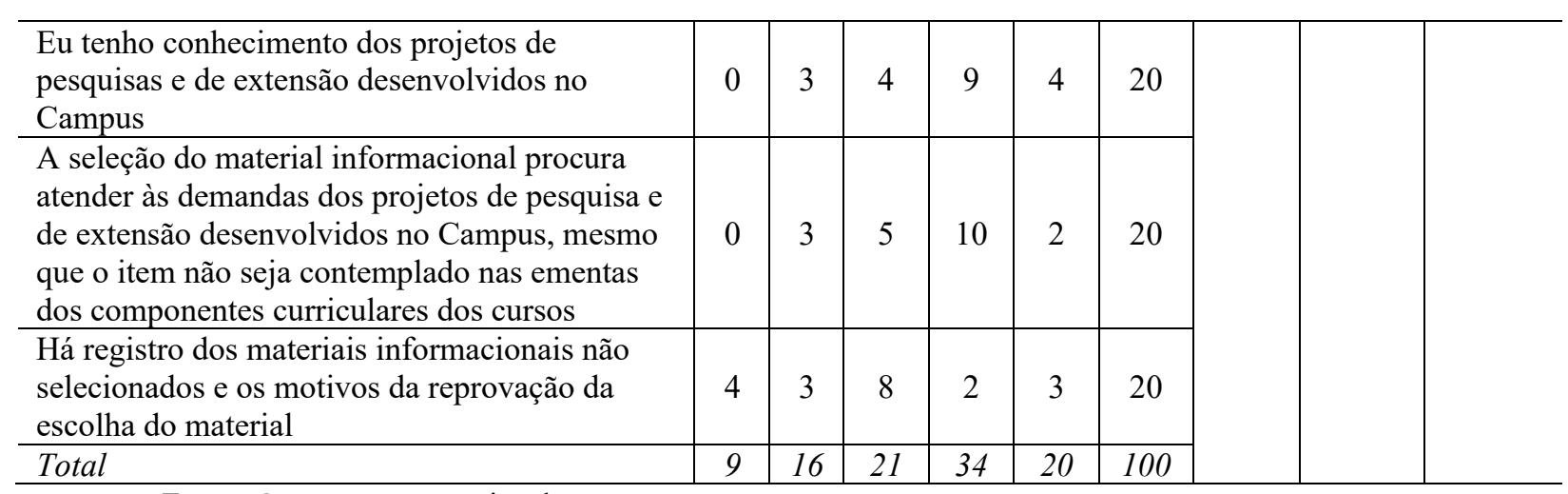

Fonte: Os autores, pesquisa de campo.

As opiniões dos questionados acerca do atendimento das demandas informacionais dos projetos de pesquisa e extensão do campus demonstram aderência à missão das bibliotecas de tipologia universitária ou especializada (MACHADO; SILVA, 2002). O tratamento direcionado aos itens informacionais selecionados devem ser compartilhados com igual rigor para os itens não selecionados como mecanismo gerencial de critérios de seleção e devidamente registrado a fim de subsidiar possíveis questionamentos futuros acerca da motivação pelo preterimento desses itens, visto possíveis mudanças de cenários e interesses institucionais.

O processo de aquisição é a concretude da formação ou desenvolvimento de uma coleção informacional (ANDRADE; VERGUEIRO, 1996). A obtenção do material informacional pode ocorrer por meio de compra, doação ou permuta (ANDRADE; VERGUEIRO, 1996; ESTABEL; MORO, 2014). Considerando o regime público do ente mantenedor das bibliotecas, o Ifba, o processo de compra deve observar a legislação pertinente quanto à licitação (BRASIL, 1988).

De acordo com os dados apresentados na tabela 4, do total de 168 respostas que compõem o fator, 56 respostas, de maneira geral, disconcordam com o fator, ao passo que 112 das respostas concordam com o ele. Pode-se, ainda, afirmar que existe uma concordância baixa dos respondentes com relação a todas as proposições do fator Aquisição de materiais informacionais. 
Tabela 4. Análise do fator Aquisição de materiais informacionais

\begin{tabular}{|c|c|c|c|c|c|c|c|c|c|}
\hline \multirow[b]{2}{*}{ Proposição } & \multicolumn{5}{|c|}{ Diferencial Semântico } & \multirow[b]{2}{*}{$\stackrel{\bar{\pi}}{\theta}$} & \multirow{2}{*}{ 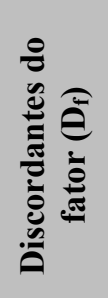 } & \multirow{2}{*}{ 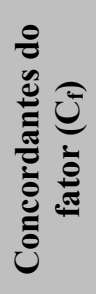 } & \multirow{2}{*}{ 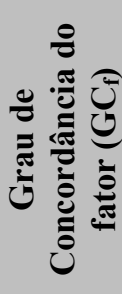 } \\
\hline & to & $\stackrel{n}{a}$ & $\begin{array}{l}7 \\
m\end{array}$ & 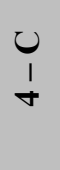 & $\begin{array}{l}5 \\
1 \\
1 \\
n\end{array}$ & & & & \\
\hline $\begin{array}{l}\text { Tendo em vista o ambiente organizacional } \\
\text { e estrutura multicampi do Ifba, há } \\
\text { cooperação de material informacional } \\
\text { entre esta biblioteca e as bibliotecas dos } \\
\text { demais campi do Ifba }\end{array}$ & 0 & 3 & 6 & 8 & 3 & 20 & \multirow{9}{*}{56} & \multirow{9}{*}{112} & \multirow{9}{*}{66,67} \\
\hline $\begin{array}{l}\text { A aquisição de material informacional } \\
\text { ocorre por meio da modalidade de compra }\end{array}$ & 0 & 5 & 5 & 9 & 9 & 20 & & & \\
\hline $\begin{array}{l}\text { A aquisição de material informacional } \\
\text { ocorre por meio da modalidade de doação }\end{array}$ & 0 & 1 & 2 & 9 & 8 & 20 & & & \\
\hline $\begin{array}{l}\text { A aquisição de material informacional } \\
\text { ocorre por meio da modalidade de } \\
\text { permuta }\end{array}$ & 8 & 3 & 4 & 3 & 2 & 20 & & & \\
\hline $\begin{array}{l}\text { Independente da forma de aquisição, por } \\
\text { meio de compra, doação ou permuta, são } \\
\text { utilizados os mesmos critérios para } \\
\text { seleção e incorporação do item } \\
\text { informacional ao acervo }\end{array}$ & 0 & 2 & 3 & 7 & 8 & 20 & & & \\
\hline $\begin{array}{l}\text { Eu conheço as normas legais acerca da } \\
\text { aquisição do material informacional, seu } \\
\text { registro patrimonial e descarte e participo } \\
\text { ativamente de todas essas atividades, } \\
\text { incluindo os processos licitatórios }\end{array}$ & 1 & 2 & 6 & 7 & 4 & 20 & & & \\
\hline $\begin{array}{l}\text { Os recursos financeiros destinados à } \\
\text { biblioteca são por ela gerenciados }\end{array}$ & 5 & 4 & 2 & 6 & 3 & 20 & & & \\
\hline $\begin{array}{l}\text { A biblioteca possui verba especial para } \\
\text { aquisição de materiais informacionais }\end{array}$ & 2 & 5 & 2 & 5 & 6 & 20 & & & \\
\hline Total & 16 & 25 & 30 & 54 & 43 & 168 & & & \\
\hline
\end{tabular}

Fonte: Os autores, pesquisa de campo.

A avaliação da coleção é o procedimento dentro do gerenciamento do acervo da biblioteca de investigação no que diz respeito ao alinhamento dos objetivos da biblioteca e da comunidade atendida, além de dar suporte às outras etapas que compõe a PDC (FIGUEIREDO, 1979b, 1998). Essa ação deve compor as rotinas administrativas e configura o perfil gerencial e decisório da biblioteca (FIGUEIREDO, 1998). De acordo com a análise da tabela 5, pode-se afirmar que na perspectiva dos partícipes da pesquisa há uma concordância desprezível no que tange à avaliação rotineira e sistemática da coleção informacional. Ou seja, essa avaliação não se traduz em uma prática cotidiana. 
O sentido geral dos respondentes, a partir do referencial semântico, é indiferente (I) à ação abordada na proposição. Dos 20 respondentes, 10 responderam discordantemente e 10 concordantemente à proposição.

Tabela 5. Análise da realização rotineira e sistemática da avaliação da coleção

\begin{tabular}{|c|c|c|c|c|c|c|c|c|c|c|}
\hline \multirow[b]{2}{*}{$\begin{array}{l}\text { A avaliação da coleção é } \\
\text { realizada de forma rotineira e } \\
\text { sistemática }\end{array}$} & \multicolumn{5}{|c|}{ Diferencial Semântico } & \multirow[b]{2}{*}{$\stackrel{\bar{\pi}}{\frac{\pi}{0}}$} & \multirow{2}{*}{ 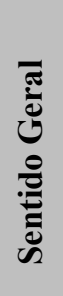 } & \multirow{2}{*}{ 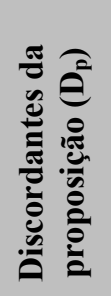 } & \multirow{2}{*}{ 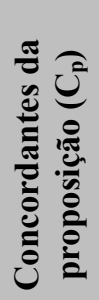 } & \multirow{2}{*}{ 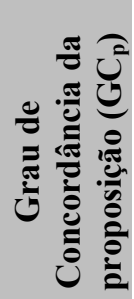 } \\
\hline & 它 & $\begin{array}{l}0 \\
1 \\
N\end{array}$ & $\vec{r}$ & $\begin{array}{l}u \\
1 \\
+\end{array}$ & $\begin{array}{c}\text { U } \\
1 \\
n\end{array}$ & & & & & \\
\hline Frequência & 0 & 8 & 4 & 4 & 4 & 20 & \multirow{2}{*}{ I } & \multirow{2}{*}{10} & \multirow{2}{*}{10} & \multirow{2}{*}{50} \\
\hline Percentual & 0 & 40 & 20 & 20 & 20 & 100 & & & & \\
\hline
\end{tabular}

Fonte: Os autores, pesquisa de campo.

Em consideração à regulação da coleção quanto aos interesses da biblioteca, Figueiredo (1998) advoga ser o desbastamento composto pelas ações de remanejamento e descarte. As perspectivas dos partícipes da pesquisa quanto à ocorrência da atividade de descarte estão expostas na tabela 6 .

Tabela 6. Análise do fator Desbastamento

\begin{tabular}{|c|c|c|c|c|c|c|c|c|c|}
\hline \multirow[b]{2}{*}{ Proposição } & \multicolumn{5}{|c|}{ Diferencial Semântico } & \multirow[b]{2}{*}{ है } & \multirow{2}{*}{ 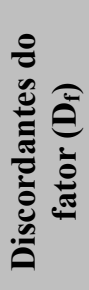 } & \multirow{2}{*}{ 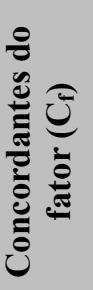 } & \multirow{2}{*}{ 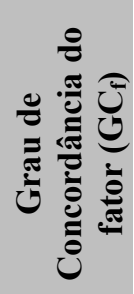 } \\
\hline & $\frac{1}{1}$ & a & m & $\begin{array}{l}u \\
1 \\
+\end{array}$ & $\begin{array}{c}\text { U } \\
1 \\
\text { n }\end{array}$ & & & & \\
\hline $\begin{array}{l}\text { O descarte de material informacional só } \\
\text { ocorre quando o item está danificado }\end{array}$ & 2 & 5 & 5 & 8 & 0 & 20 & \multirow{4}{*}{13,5} & \multirow{4}{*}{46,5} & \multirow{4}{*}{77,5} \\
\hline $\begin{array}{l}\text { A biblioteca adota medidas de } \\
\text { conservação das coleções }\end{array}$ & 0 & 0 & 3 & 12 & 5 & 20 & & & \\
\hline $\begin{array}{l}\text { A biblioteca já realizou atividades com } \\
\text { vista a preservação da coleção } \\
\text { informacional }\end{array}$ & 0 & 1 & 3 & 10 & 6 & 20 & & & \\
\hline Total & 2 & 6 & 11 & 30 & 11 & 60 & & & \\
\hline
\end{tabular}

Fonte: Os autores, pesquisa de campo.

De acordo com os dados da tabela 7, o sentimento predominante dos questionados é de concordância total $(\mathrm{CT})$ quanto à relação existente entre a competência no que tenge à práticas e metodologias de pesquisa, capacitação e qualificação continuadas serem eficazes para o gerenciamento da coleção. Essa perspectiva é reafirmada com o valor de $C_{p}$, já que 19 dos 20 questionados responderam concordantemente e o valor do $\mathrm{GC}_{\mathrm{p}}$ que indica a existência de uma concordância muito forte para a proposição em comento. 
Para Machado e Santos (2002) a atualização do profissional no que se refere às técnicas de preservação e conservação, com destaque para os materiais especiais, são requisitos essenciais, reverberando no processo de descarte dos itens informacionais. Igualmente atualizado devem estar os profisssionais quanto às técnicas de bibliometria - para avaliação quanto a obsolescência do acervo, legal e de metodologias científicas para suportar todos o gerenciamento informacional (FIGUEIREDO, 1979a, 1998).

Tabela 7. Análise da correlação entre a educação continuada e o gerenciamento da coleção

\begin{tabular}{|c|c|c|c|c|c|c|c|c|c|c|}
\hline \multirow{2}{*}{$\begin{array}{l}\text { Conhecimentos sobre práticas e } \\
\text { metodologias de pesquisa, } \\
\text { capacitação e qualificação } \\
\text { continuadas são essenciais para } \\
\text { o gerenciamento da coleção }\end{array}$} & \multicolumn{5}{|c|}{ Diferencial Semântico } & \multirow[b]{2}{*}{ స్ } & \multirow{2}{*}{ 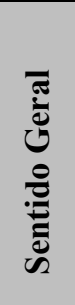 } & \multirow{2}{*}{ 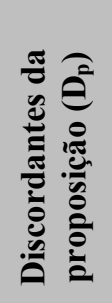 } & \multirow{2}{*}{ 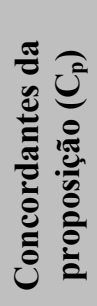 } & \multirow{2}{*}{ 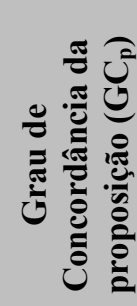 } \\
\hline & $\underline{\hat{1}}$ & $\begin{array}{l}0 \\
1 \\
\sim\end{array}$ & $\begin{array}{l}T \\
\text { no }\end{array}$ & $\begin{array}{l}u \\
\text { I }\end{array}$ & $\begin{array}{l}y \\
1 \\
1 \\
\text { s }\end{array}$ & & & & & \\
\hline Frequên & 0 & 8 & 2 & 5 & 13 & 20 & \multirow{2}{*}{$\mathrm{CT}$} & & \multirow{2}{*}{19} & \multirow{2}{*}{95} \\
\hline Percentual & 0 & 0 & 10 & 25 & 65 & 100 & & & & \\
\hline
\end{tabular}

Fonte: Os autores, pesquisa de campo.

O quadro 2 sintetiza o grau de concordância da população com as variáveis eleitas para analisar as perspectivas dos responsáveis das bibliotecas dos campi do Ifba acerca do desenvolvimento do acervo informacional.

Quadro 2. Grau de concordância acerca das variáveis de desenvolvimento do acervo informacional

\begin{tabular}{|l|c|c|}
\hline \multicolumn{1}{|c|}{ Variáveis } & $\mathbf{G C}_{\mathbf{p}} / \mathbf{G C}_{\mathbf{f}}$ & Frase Adequada \\
\hline Estudo de comunidade & 0,0 & Uma discordância forte \\
\hline Política de Desenvolvimento da Coleção & 47,5 & Uma discordância desprezível \\
\hline Seleção de materiais informacionais & 64,5 & Uma concordância baixa \\
\hline Aquisição de materiais informacionais & 66,67 & Uma concordância baixa \\
\hline Avaliação da Coleção & 50,0 & Uma concordância desprezível \\
\hline Desbastamento & 77,5 & Uma concordância moderada \\
\hline Educação continuada & 95,5 & Uma concordância muito forte \\
\hline
\end{tabular}

Fonte: Os autores, pesquisa de campo.

A partir da análise dos resultados de pesquisa e a correlação entre as variáveis escolhidas neste trabalho acerca o tema Formação e Desenvolvimento de Coleções de bibliotecas, a aderência da pesquisa quanto às hipóteses do estudo, com base no que foi coletado, será abordada no capítulo que se segue. 


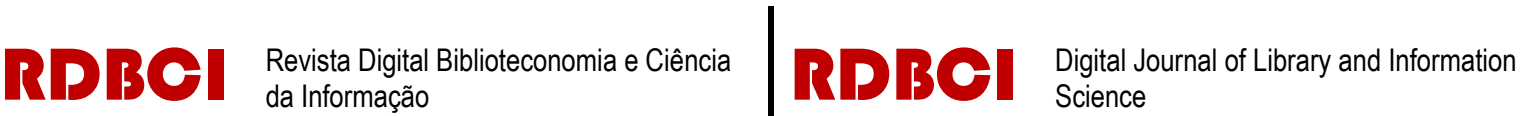

\section{CONSIDERAÇõeS E CONCLUS̃̃ES}

O propósito desta pesquisa consistiu na percepção dos responsáveis das bibliotecas dos campi do Ifba acerca dos processos de formação ou desenvolvimento de sua coleção de materiais informacionais. A resposta à pergunta de partida incidiu que na visão desses representantes, as bases teóricas acerca do tema eram empregadas com parcimônia (H1) e que não assentia a construção do acervo informacional colaborativo das bibliotecas, apesar da estrutura multicampi da autarquia (H2). Em outras palavras, as ações de uma biblioteca não eram compartidas pelas demais, em um mecanismo de sistema.

O modelo de análise foi constituído a partir de variáveis definidas, de acordo com a teoria diretamente relacionada ao gerenciamento de coleção informacional, e variáveis de controle, que embora não se limitem ao tema podem esclarecer a opinião e, por conseguinte, a ação do responsável pela biblioteca. Os resultados observados demonstraram que, do ponto de vista dos respondentes, não há homogeneidade de observação aos ditames teóricos acerca da formação e desenvolvimento de coleções de bibliotecas.

No que tange ao tópico acerca do estudo de comunidade, a população rechaçou positivamente a hipótese de que este assunto é seguido moderadamente ao indicar que há uma adesão muito forte aos preceitos teóricos (H1). A variável acerca da educação continuada segue esse mesmo panorama de rechaço à perspectiva de moderamento de valor (H1).

Apesar da aderência aos preceitos teóricos, quanto às variáveis adequadas à seleção, aquisição e desbastamento de materiais informacionais, essas vertentes do estudo matizam a hipótese de observância moderada das suas bases teórico-conceituais, convergindo para os resultados esperados e comprovando a primeira hipótese (H1). Uma justificativa plauzível para esse resultado é a experiência desses representantes quanto ao trabalho em bibliotecas e, mais especificamente, a prática em chefia de bibliotecas, visto que muitos dos respondentes se encontram no tirocínio dessa fase profissional. Associado ao elemento experiência profissional está a fase de expansão vivenciada pela autarquia, a partir do ano 2008 que culminou na inauguração de vários campi localizados em distintos municípios do estado da Bahia e, portanto, ainda sem infraestrutura satisfatória, em especial nas localidades mais interioranas.

No que tange à PDC e à avaliação da coleção, esses componentes rechaçam negativamente a hipótese (H1) ao alcançar concordância baixa em comparação aos ensinamentos teóricos de gerenciamento de coleção.

Na opinião dos representantes das bibliotecas do Ifba, suas unidades cooperaram e são cooperadas pelas demais bibliotecas da autarquia. Dessa forma, é rejeitada a hipótese quanto a

\begin{tabular}{l|l|l|l|l|l|}
\hline (C) RDBCl: Rev. Digit. Bibliotecon. Cienc. Inf. & Campinas, SP & v.17 & $1-21$ & e019001 & 2019 \\
\hline
\end{tabular}


formação cooperativa e participativa da coleção (H2). Não obstante, apesar de não representar uma hipótese para a pesquisa, os partícipes do estudo tendem a concordar que a cooperação com outras instituições acontece de forma insuficiente, caso seja adotada para esse fim a aquisição de material informacional por permuta.

A principal contribuição deste trabalho está nas ponderações sobre o acervo informacional da autarquia, artefato primordial para subsidiar o sucesso de uma instuição que possui como atividade fim a promoção da educação, da pesquisa e da extensão. Essa premissa se aplica diretamente ao Ifba e indiretamente a toda a rede de ensino técnico e tecnológico em expansão.

Aplica-se, ainda, nesse conjunto de reflexão, o melhoramento de rotinas administrativas para a cooperação entre as diversas bibliotecas, compartilhamento dos recursos informacionais, financeiros e de investimentos na sua infraestrutura de bibliotecas, assim como para o avanço de cooperação inter-instituicional.

As sugestões de estudos vindouros se concentram no alargamento da vertente quantitativa da metodologia e perpassa para uma pesquisa inclusiva de análise qualitativa e individualizada, tanto no sentido do campus quanto no que se refere ao profissional, e que considere as diferenças regionais, culturais e sócio-econômicas presentes em cada município no qual a biblioteca está localizada.

As limitações para realização deste estudo estão concentradas na falta de uniformização da estrutura administrativa da autarquia e de seus campi. Em alguns momentos foi verificada que a representatividade da biblioteca acontece mais pela prática do que pela designação oficial, contrariando os ditames legais que empoderam o agente para tomada de decisão e, em função dessa constatação, podem haver vieses cognitivos nas respostas, já que o questionado não se sente confortável no instante da tomada de decisão e por consequência a ação pode não corresponder à sua opinião mais concreta.

\section{REFERÊNCIAS}

ANDRADE, D.; VERGUEIRO, W. Aquisição de materiais de informação. Brasília, DF: Briquet de Lemos/Livros, 1996.

BRASIL. Lei n ${ }^{\circ} 4.084$, de 30 de junho de 1962. Dispõe sobre a profissão de bibliotecário e regula seu exercício. Disponível em: http://www.planalto.gov.br/ccivil_03/leis/19501969/L4084.htm. Acesso em: 26 set. 2016. 
BRASIL. Constituição (1988). Constituição da República Federativa do Brasil.

Disponível em: http://www.planalto.gov.br/ccivil_03/constituicao/constituicaocompilado. htm. Acesso em: 3 ago. 2016.

BRASIL. Ministério do Planejamento, Orçamento e Gestão. Secretaria de Gestão Pública. Ofício Circular $n^{\circ}$ 01/2012/SEGEP-MP, de 15 de fevereiro de 2012. Observância às normas que regulamentam a profissão de Bibliotecário. Disponível em:

https://conlegis.planejamento.gov.br/conlegis/pesquisaTextual/atoNormativoDetalhesPub.ht $\underline{\mathrm{m} ? \mathrm{id}=8890}$. Acesso em: 27 set. 2016.

BURKE, P. Problemas causados por Gutenberg: a explosão da informação nos primórdios da Europa moderna. Trad. de Almiro Piseta. Estudos Avançados. São Paulo, v. 16, n. 44, janeiro-abril 2002. Disponível em: http://www.scielo.br/scielo.php?pid=S010340142002000100010\&script=sci_arttext. Acesso em: 11 jun.2015.

DIRETORIA DE AVALIAÇÃO DO ENSINO SUPERIOR (DAES). Instrumento de avaliação de cursos de graduação: presencial e a distância. Brasília, 2015.

ESTABEL, L. B.; MORO, E. L. S. Tratamento do livro: seleção, aquisição e organização do acervo da biblioteca. In: ESTABEL, L. B.; MORO, E. L. S. (org.). Biblioteca:

conhecimentos e práticas. Porto Alegre: Penso, 2014. p. 14-41.

EVANS, E. G. Developing library and information centre collections. 3er.ed. Englewond: Libraries Unlimited, 1995.

FIGUEIREDO, N. M. Bibliotecas universitárias e especializadas: paralelos e contrastes.

Revista Biblioteconomia, Brasília, v. 7, n. 1, p. 09-25, jan.-jun. 1979a. Disponível em: http://www.brapci.ufpr.br/documento.php? $\mathrm{dd} 0=0000002354 \& \mathrm{dd} 1=\mathrm{bb} 4 \mathrm{c} 3$. Acesso em: 27 out. 2015.

FIGUEIREDO, N. M. Avaliação de coleções e estudo de usuários. Brasília: Associação dos Bibliotecários do Distrito Federal, 1979b.

FIGUEIREDO, N. M. Desenvolvimento e avaliação de coleções. 2. ed. Brasília: Thesaurus, 1998.

HOFFMANN, F. W.; WOOD, R. J. Library collection development policies: Academic, public, and special libraries. Scarecrow Press, Lanham, 2005.

KENNEDY, J. Collection management: a concise introduction. Wagga: Centre for Information Studies, Charles Sturt University, 2006. 
LORENZEN, M. Information policy as library policy: intellectual freedom. Lecture \# 20, Spring/Summer, 2009. (LIS 6010 WSU/LISP).

MACHADO, R. N.; SANTOS, S. S. Coleção de lastro: uma avaliação do estado de conservação. In: ENCONTRO NACIONAL DE ENSINO E PESQUISA EM INFORMAÇÃO, 9., 2009, Salvador. Anais eletrônicos... Salvador: UFPE, 2002. Disponível em: http://api.ning.com/files/AwOyT6gC1eFqxzjvmeMmauyLmP0XDe8BTZaLqGCr6 WjtqAgJmSjgjRYoFzzNpHVcHJZVWkeblCSzahf2dyrhRYLqWRM-501n/ArtigoSelma SantosIXCINFORM.pdf. Acesso em: 24 ago. 2016.

QUIVY, R.; CAMPENHOUDT, L. Manual de investigação em ciências sociais. 2. ed. Lisboa: Gradiva, 1998.

RIBEIRO, F. Da mediação passiva à mediação pós-custodial: o papel da Ciência da Informação na sociedade em rede. Informação \& Sociedade: Estudos, João Pessoa, v.20, n.1, p. 63-70, jan./abr. 2010. Disponível em:

http://www.ies.ufpb.br/ojs/index.php/ies/article/view/4440/3420. Acesso em: 11 jun. 2015.

SANCHES, C.; MEIRELES, M.; DE SORDI, J. O. Análise qualitativa por meio da lógica paraconsistente: método de interpretação e síntese de informação obtida por escalas Likert. In: ENCONTRO DE ENSINO E PESQUISA EM ADMINISTRAÇÃO E CONTABILIDADE, 3., 2011, João Pessoa. Anais eletrônicos... João Pessoa: Anpad, 2011. Disponível em: http://www.anpad.org.br/diversos/trabalhos/EnEPQ/enepq 2011/ ENEPQ221.pdf. Acesso em: 30 ago. 2016.

VERGUEIRO, W. Desenvolvimento de coleções: uma nova visão para o planejamento de recursos informacionais. Ciência da Informação. Brasília, v. 22, n. 1, p. 13-21, jan.-abr. 1993.

VERGUEIRO, W. Seleção de materiais de informação: princípios e técnicas. 3. ed. Brasília, DF: Briquet de Lemos/Livros, 2010.

WEITZEL, S. R. O desenvolvimento de coleções e a organização do conhecimento: suas origens e desafios. Perspectivas em Ciência da Informação, Belo Horizonte, v.7, n.1, p.6167, jan./jun., 2002.

WEITZEL, S. R. Desenvolvimento de coleções: origem dos fundamentos contemporâneos. TransInformação, Campinas, v. 24, n. 3, p. 179-190, set./dez., 2012. Disponível em: http://www.scielo.br/pdf/tinf/v24n3/a03v24n3.pdf. Acesso em: 11 jun. 2015.

\footnotetext{
*Este artigo é um extrato do trabalho monográfico ganhador do $1^{\circ}$ lugar no Concurso TCC -2017 realizado pela Associação Brasileira de Ciência da Informação (ABECIN), na categoria Curso de Biblioteconomia da Região Nordeste.

\begin{tabular}{c|c|c|c|c|}
\hline C ( RDBCl: Rev. Digit. Bibliotecon. Cienc. Inf. & Campinas, SP & v.17 & $1-21$ & e019001
\end{tabular}
2019
} 